\title{
SEXUALIDAD, CUERPO Y PODER: DEL GOBIERNO DE LA CARNE AL GOBIERNO DE LAS POBLACIONES ${ }^{1}$
}

\section{SEXUALITY, BODY AND POWER: FROM THE GOVERNMENT OF THE FLESH TO THE GOVERNMENT OF THE POPULATIONS}

\author{
Camilo Retana Alvarado \\ camiloretana@gmail.com \\ Universidad de Costa Rica
}

Recibido: 12 de mayo de 2018 • Aceptado: 30 de mayo de 2018 - Publicado: 9 de octubre de 2018

\begin{abstract}
Resumen
El presente escrito brinda una reflexión surgida en el contexto del último proceso electoral llevado a cabo en Costa Rica, en febrero del 2018. Específicamente, presenta líneas de análisis para abordar la forma en la que la sexualidad se ha convertido en una zona privilegiada de la vida social, cuando de gestionar y controlar los cuerpos de los individuos se trata, así como el comportamiento de las poblaciones que estos conforman. Para ello, se revisan las nociones de cuerpo y sexualidad, su permeabilidad a las prácticas sociales y, por lo tanto, su susceptibilidad a la transformación, la manipulación, la gestión y la dirección, en tanto operan como ejes de gobierno. Luego, se pasa a analizar la sexualidad como espacio de "gubernamentalidad", relacionada con administraciones localizadas o "micro", para llegar al reflejo de ello en los debates electorales, centrados de manera unilateral en cuestiones referidas a la sexualidad, dejándose de lado otras más decisivas.
\end{abstract}

Palabras clave: cuerpo, sexualidad, gubernamentalidad, diversidad sexual, Costa Rica.

1 Este texto es resultado de una conferencia pronunciada el 10 de mayo de 2018, en el marco de los Diálogos Humanistas organizados por el Sistema de Educación General de la Sede de Occidente de la Universidad de Costa Rica. 


\begin{abstract}
This paper provides a reflection that emerged in the context of the last electoral process carried out in Costa Rica, in February 2018. Specifically, it presents lines of analysis to address the way in which sexuality has become a privileged area of social life, when it comes to managing and controlling the bodies of individuals, as well as the behavior of the populations they make up. To this end, the notions of body and sexuality are reviewed, along with their permeability to social practices and, therefore, their susceptibility to transformation, manipulation, management and direction, as they operate as axes of government. Then, it analyzes sexuality as a space of "governmentality", in relation to localized or "micro" administrations, to arrive at its reflection in the electoral debates, focused unilaterally on issues related to sexuality, leaving aside other more decisive ones.
\end{abstract}

Keywords: body, sexuality, governmentality, sexual diversity, Costa Rica.

El título de este escrito puede llamar a engaños al emplear un lenguaje, aparentemente técnico, que, además, remite a reflexiones realizadas por un historiador francés en función de explicar procesos históricos fundamentalmente europeos. Así las cosas, se podría pensar que mi objetivo hoy es hablar de cosas técnicas ajenas a nuestro contexto. Sin embargo, mi idea es hacer exactamente lo opuesto: quisiera servirme de ese vocabulario sin dotarlo de un sentido excesivamente técnico, con el fin de reflexionar sobre algunas cosas que ocurrieron en Costa Rica en los últimos tiempos. En particular, me gustaría presentar algunas líneas de análisis que creo podrían resultar útiles para indagar el modo en que la sexualidad se ha convertido en una zona privilegiada de la vida social, a la hora de gestionar y controlar los cuerpos de los individuos y el comportamiento de las poblaciones que estos conforman. Mi objetivo es generar diálogo a partir de esas líneas de análisis.

Comencemos con algunas aclaraciones preliminares. Cuando se habla de la sexualidad y el cuerpo, usualmente se asocian esas nociones con la naturaleza y lo dado. Normalmente pensamos que tenemos un cuerpo (como si fuésemos distintos de él) y que ese tiene unos deseos sexuales signados por una constitución que le es inherente. Dicho de otro modo, la sexualidad y el cuerpo son vistos a menudo como realidades que no podemos cambiar, que no elegimos, que llevamos un poco a cuestas. De vez en cuando, algún médico, algún sexólogo o psicólogo puede que intervenga un poco en nuestro 
cuerpo o nuestro comportamiento sexual y cambie algo en nosotros mediante alguna prescripción o medicamento, pero se supone que lo hace en nombre de restituir nuestra salud, es decir, de devolverle su configuración natural. En el centro de nuestro cuerpo sexuado, se encuentra así la creencia de que hay una verdad intrínseca que nos habita y que nos debemos limitar a respetar.

Con base en lo anterior, pareciera una tarea ociosa ocuparse del cuerpo por fuera del campo científico. ¿Que podrían decir del cuerpo la filosofía, las ciencias sociales o la literatura que no puedan decir con mayor claridad y certidumbre otras ciencias más exactas? ¿Qué decir del cuerpo por fuera de las descripciones que de él podamos hacer? En realidad, estas preguntas presuponen precisamente lo que quisiera que comenzáramos por cuestionar, a saber, si en verdad el cuerpo sexuado constituye una instancia independiente de aquello que decimos sobre él. ¿No ocurre, por el contrario, que cuando hablamos de los cuerpos y los sexos estamos en cierto sentido delineando lo que esos cuerpos y sexos son?

Volvamos sobre el ejemplo del médico: cuando este nos examina y determina que algo no anda bien en nuestro organismo, usualmente lo hace desde un paradigma científico que opone lo saludable a lo enfermo. Típicamente, lo sano está asociado por lo demás a lo normal y lo patológico a lo anormal (Canguilhem, 2011). En otras palabras, cuando un médico nos examina y nos prescribe unos comportamientos o unas pastillas, lo hace partiendo de que hay cuerpos, funcionamientos y comportamientos normales en contraposición a otros anormales. Pero ocurre que inclusive la medicina, con todo y sus métodos aparentemente infalibles, tiene una historia que no siempre es la de su progresivo perfeccionamiento. En realidad, la historia de la medicina está poblada de ejemplos que muestran cómo los parámetros de normalidad y anormalidad (y con ellos los parámetros de lo sano y de lo insano) cambian constante y, a veces, repentinamente, de una época histórica a otra. La gordura, por ejemplo, no se consideró un problema de salud sino hasta el ocaso de la Edad Media, cuando se volvieron menos frecuentes las hambrunas y se comenzó a instalar la imagen del cuerpo delgado como el cuerpo sano por excelencia (Vigarello, 2011). Esa visión, a la vez, ha entrado en crisis en las últimas décadas, en la medida en que cada vez más personas (usualmente jóvenes mujeres) son diagnosticadas de anorexia, con lo cual la extrema delgadez comienza a asociarse cada vez con mayor frecuencia a la enfermedad. 
Por supuesto, no pretendo sugerir que se desista de ir al médico cuando sea necesario. Tan solo quisiera destacar el hecho de que cuando un médico nos trata, se esfuerza, a menudo sin saberlo, por adecuar nuestro cuerpo a un arquetipo, modelo o paradigma corporal que tiene una historia no siempre ordenada, ni siempre orientada hacia la superación de sus propios errores. Por el contrario, cuestiones ajenas a la ciencia - como la guerra, la moda, la alimentación, el deporte, etc.- - a menudo inciden en cómo esta imagina al cuerpo. Lo mismo podemos decir de la sexualidad, pues constantemente nuestras prácticas, gustos, temores y repelencias en materia sexual están dadas por el contexto histórico y geográfico en que vivimos. La cultura heterosexual, por ejemplo, no se torna una institución dominante sino a partir del siglo XII (Tin, 2012). El matrimonio se plantea como base de la sociedad occidental tan solo partiendo del mundo latino y de la expansión del cristianismo (Foucault, 2004). La masturbación infantil se torna un problema apenas a mediados del siglo XIX (Foucault, 2002). Y la pornografía, que se supone es un acercamiento casi documental a la sexualidad, varía en sus motivos y los cuerpos que presenta casi que de década tras década (Echavarren, 2009).

Con esto lo que quiero decir es que el sexo y el cuerpo no son impermeables a los discursos y las prácticas. De hecho, nuestras percepciones, costumbres y acciones cotidianas, aunadas a las instituciones y normas históricas que nos rodean, definen en buena medida lo que nuestros cuerpos sexuados desean y son. El cuerpo y el sexo no son realidades independientes de la historia, la sociedad y la cultura, sino que se fraguan, en parte, al calor de las disputas históricas, sociales y culturales que se libran alrededor suyo.

Lo anterior quiere decir que el cuerpo y el sexo son susceptibles a la transformación, la manipulación, la gestión y la dirección. En otras palabras, el cuerpo y el sexo son frecuentemente regulados y controlados mediante un conglomerado de conocimientos, creencias, dogmas, estereotipos e instituciones. Dicho en breve: la corporalidad y la sexualidad son dominios en los cuales entran a jugar relaciones de poder. Me refiero sencillamente al hecho de que no hay individuo que no se forje a sí mismo al interior de un 
determinado campo de fuerzas que limita — pero también posibilita— lo que ese individuo puede llegar a ser. Las relaciones de poder son, pues, lo que acaece al interior de dicho campo. Si pensamos en un sexólogo que opina sobre la sexualidad de su paciente prescribiéndole qué comportamientos sexuales debe o no realizar, no hay duda de que ejerce un poder sobre su paciente, especialmente cuando ese desea precisamente lo que el sexólogo le prohíbe (Béjin, 1987). Esto no implica que el poder sea un designio maligno que nos impide hacer todo lo que desearíamos, pues, pese a que nos limita, también es un hecho que nos habilita a ejercer una influencia a veces necesaria sobre los otros (aún cuando esa influencia se vea menguada tan a menudo, en especial cuando ocupamos un rol de subordinación como el de los hijos en relación con los padres, los estudiantes en relación con los profesores o los feligreses en relación con sus curas). Así, el poder no es algo que ocurre allá lejos, fuera de nuestro radio de influencia: todos, de alguna u otra manera, ejercemos poder sobre otros y también lo padecemos, aunque unas veces esa experiencia sea más terrorífica que otras. En todo caso, el poder es un agente regulador de las relaciones sociales, y el hecho de que existan abusos de autoridad no quiere decir que debamos deshacernos del poder, sino transformarlo para que su ejercicio no resulte lacerante.

\section{$*$}

Si, como acabo de argumentar, el cuerpo y la sexualidad son susceptibles de manipulación a través de relaciones de poder, querría ahora entrar a analizar el modo específico en que esas relaciones de poder operan en dos planos: el individual y el colectivo. Dicho de otra forma, quisiera intentar diferenciar - para luego relacionar - el modo en que el cuerpo y el sexo operan como ejes de gobierno, tanto de la carne como de las poblaciones.

Sin embargo, antes debo referirme a un concepto que acabo de introducir de súbito sin ofrecer mayores explicaciones: el de gobierno. Por este me refiero a algo bastante cercano a lo que he entendido antes por poder. Mejor dicho: el gobierno es una de las modalidades del poder, una de las formas en que este se ejerce o se practica (Foucault, 2009). De hecho, todos estamos familiarizados con la palabra gobierno, porque así es como llamamos en Costa Rica al conjunto de instituciones ligadas al poder ejecutivo. No obstante, 
esta veta colectiva de lo que, si me permiten, llamaré "gubernamentalidad" —utilizando un concepto de Michel Foucault, el historiador francés al que me referí al comienzo- no agota el asunto. El gobierno es, de hecho, algo que no termina en el poder ejecutivo y el conjunto de sus ministerios. Hay una veta, si se quiere más inmediata de la "gubernamentalidad", que tiene que ver con administraciones localizadas o "micro". En sus primeras acepciones en el mundo grecorromano, el gobierno era algo que se predicaba de una serie de relaciones mucho más individualizadas. Por ejemplo, un padre estaba llamado a gobernar su casa y su familia. Un adulto estaba llamado a gobernar a los jóvenes a su cargo. Un maestro debía poder gobernar a sus discípulos. $\mathrm{O}$, en el ejemplo privilegiado, el pastor debía gobernar a sus ovejas.

Pero, estas primeras acepciones de gobierno incluían una faceta que progresivamente se fue dejando de lado. Me refiero al hecho de que la preocupación por el gobierno fue, en sus inicios, sobre todo una preocupación por el gobierno de uno sobre uno mismo. En otras palabras, gobernar no constituía únicamente un ejercicio unidireccional hacia un subordinado o súbdito, sino que aprender a gobernar abarcaba también aprender el arte de gobernarse a sí mismo. Una máxima antigua, incluso, rezaba que uno no podía gobernar a otro hasta tanto no fuera capaz de gobernarse a sí mismo. En todo caso, el hecho es que gobernar no ha sido siempre únicamente gobernar a otro, no ha sido siempre sinónimo de poder. Con la cristianización de la sociedad occidental y la consolidación de los Estados Modernos (y acá estoy siendo excesivamente laxo con los períodos y fases históricas, con tal de no sacrificar claridad en la exposición), lo que ocurre es que el gobierno se torna una forma de poder mucho más vertical, ligada ante todo al control de los colectivos - y en particular, en el caso de los Estados Nacionales, vinculada al gobierno de las poblaciones que habitan un determinado territorio (Foucault, 2009)-.

En resumen, el gobierno es una forma de poder que involucra, en el nivel histórico, tanto el autogobierno - progresivamente dejado de ladocomo el gobierno de los otros — cada vez más relevante (Foucault, 2010)—. Este movimiento histórico coincide con una diversificación moderna de las formas de poder (Butler y Spivak, 2009). En concreto - y de nuevo les ruego que me perdonen la laxitud- el gobierno de las poblaciones queda fundamentalmente a cargo de los Estados/Nación y el gobierno de los individuos 
se gestiona desde instituciones que podríamos llamar "paraestatales", como la familia, la Iglesia, la pareja, la amistad o la clínica. Hablo de una diversificación porque, en las sociedades europeas premodernas, el gobierno de las almas era una tarea de la Iglesia y el gobierno monárquico cogobernaba esas almas en contubernio con el poder eclesial. Con la separación del Estado y la Iglesia, al igual que con el surgimiento de los Estados laicos, en cambio, estos deben ocuparse de gobernar las poblaciones, mientras que los individuos quedan en manos de otras formas de poder no necesariamente estatales (en buena teoría, un Estado Moderno se limita a hacer que los gobernados respeten la ley, puesto que, a través de esa obediencia a una legislación que ellos mismos han elegido, también podrán gobernarse a sí mismos satisfactoriamente).

No obstante, a menudo esas dos escalas del poder, la individual y la poblacional, se correlacionan entre sí. Por ofrecer solo un ejemplo breve, los Estados administran las escuelas, que a su vez gobiernan, mediante los maestros, a los niños. La salud, por otra parte, se considera un problema público, aunque al interior de los hospitales se controla a los individuos en un nivel micro. Es en el marco de estas correlaciones entre gobierno de las poblaciones y gobierno de los individuos que la sexualidad se erige como un campo de poder fundamental, pues es en ella donde más intersecciones ocurren entre una y otra forma de gobierno. La sexualidad es siempre un problema de gobierno individual, al mismo tiempo que un problema de gobierno de las poblaciones (Foucault, 2005). Esto obedece a una serie de particularidades históricas, pero en el contexto de esta conferencia basta con decir que la sexualidad atañe por igual a los Estados que a los sujetos individuales, y que no se puede gestionar desde un solo flanco, porque para controlar la sexualidad de la población es necesario poder controlar la de los individuos que la componen.

Esto no ocurre con otros enclaves de poder: un Estado, por ejemplo, puede administrar las finanzas de la población, pero el control que el individuo hace de su dinero no es asunto de aquel, salvo que cometa un fraude. De la misma manera, los Estados deben ocuparse de los flujos migratorios, pero no es asunto suyo adónde va un ciudadano que se encuentra legal en un territorio, a menos que cometa algún delito. En el caso de la sexualidad, en cambio, el comportamiento individual impacta directamente la sociedad 
como un todo; de ahí que los Estados se abroguen la capacidad de prohibir el aborto o de indicar — no es el caso de Costa Rica - cuántos hijos debe tener una pareja, o bien de establecer qué prácticas sexuales son morales y cuáles no lo son. En lo tocante a la sexualidad, pues, gobernar el cuerpo es asimismo gobernar la población.

Ustedes se preguntarán por el sentido de este tedioso aunque somero recorrido histórico que acabo de hacer, cuando prometí al inicio hablar de Costa Rica. Perdonen si los he defraudado. Ocurre, sin embargo, que creo que no podemos comprender a cabalidad lo que acaba de ocurrir en las elecciones presidenciales del 2018, sin hacer un mapeo breve de las cuestiones previas. Me refiero al hecho de que, como tantas veces se dijo en los últimos meses, la elección anterior enfrentó dos visiones de país y dos proyectos de sociedad completamente antagónicas. No quisiera limitarme aquí a decir por qué una me parece mejor que la otra. Más bien, quisiera explicar, a partir de mis argumentos mencionados, cómo es que fue posible tal dicotomía.

Si tal y como he defendido antes lo propio de las sociedades modernas es delegar el gobierno de los individuos a instituciones "paraestatales" y superar el gobierno pastoral de la Iglesia de antaño (en la que, insisto, el gobierno de las almas era uno solo y en el que el pastor/rey tenía la posibilidad de gobernar la totalidad de la vida de sus "ovejas"), lo que ocurre en sociedades con proyectos de modernidad fallidos como el nuestro (si es que cabe hablar de modernidades fallidas, cuando ningún proyecto moderno llegó a coagular completamente alguna vez), es que la Iglesia continúa teniendo una importancia fundamental en las cosas del Estado. En Costa Rica, nunca ha aplicado del todo aquello de que "a Dios lo que es de Dios y al César lo que es del César”. Esto no representa obligatoriamente un problema (aunque estoy consciente de que para muchos sectores progresistas de la sociedad sí que lo es), pero en Costa Rica, históricamente, sí que lo ha representado. De hecho, lo que ha pasado en el país es que las oligarquías económicas y los sectores poderosos han gobernado de mutuo acuerdo con las jerarquías de la Iglesia. Para decirlo con una metáfora: el pastel estaba bien repartido y, a menos de que alguien reclamara una tajada que no correspondía, la Iglesia 
y los sectores corporativos han mantenido un acuerdo de no agresión que les ha beneficiado mutuamente.

Con la descomposición del Estado a finales del siglo pasado, la mala administración de las instituciones y el deterioro del tejido institucional (aprobación del TLC, corrupción de los altos mandos de gobiernos del PUSC y el PLN, crisis de la CCSS y privatización de bienes y servicios sensibles), la cercanía entre las élites económicas y eclesiales empieza a entrar en crisis. Por un lado, los gobernantes del Estado empiezan a revelar su incapacidad a la hora de administrar la cosa pública; por otro, ese movimiento coincide con la pérdida de influencia de una Iglesia católica cada vez menos "conectada" con las necesidades de la gente y con el despliegue de una sociedad informatizada, donde la retórica católica empieza a quedar cada vez más relegada, al lo menos en entornos urbanos. Toda esta coyuntura — que, una vez más, solo estoy sobrevolando- produce una profunda crisis de gubernamentalidad. En otras palabras: los sectores históricamente llamados a gobernar a los individuos y a las poblaciones se revelan cada vez menos capacitados para hacerlo.

Esto genera las condiciones necesarias para que un discurso autoritario como el de Fabricio Alvarado y Restauración Nacional se presenten como una alternativa viable para un sector amplio de la sociedad. Es decir, si la crisis en las instituciones costarricenses de referencia (élites clericales y económicas) genera un vacío de gobernabilidad, un discurso que, como el de Fabricio Alvarado, promete restaurar esas instituciones y restituir las antiguas lógicas autoritarias de gobierno llena perfectamente ese vacío. Fabricio se presentaba, literalmente, como el pastor capaz de devolver al redil a sus ovejas. Así, RN no solo auguraba recomponer el deterioro en las instituciones abocadas a gobernar las poblaciones, sino que también planteaba devolver a las familias, los padres, la policía y los maestros la legitimidad gubernamental que han venido perdiendo. Se trataba de volver a unificar ambas formas de gobierno bajo el amparo de la figura del pastor/gobernante, es decir, de gobernar el país al tiempo que se gobiernan las almas. En todo ello, la sexualidad se presenta como un eje fundamental, puesto que, como ya dije, esta constituye un punto de contacto fundamental entre el gobierno de los cuerpos y el de las poblaciones. 
En efecto, dado el hecho de que la sexualidad no ha dejado de ser nunca en nuestras sociedades una forma tanto de controlar a los individuos como a las poblaciones, se plantea como un espacio de gubernamentalidad con consecuencias en la totalidad de la vida social. En este sentido, existió un equívoco que se repitió hasta el cansancio en el contexto de la recién finalizada campaña presidencial. Me refiero a la queja según la cual los debates se habían centrado, de manera unilateral, en cuestiones referidas a la sexualidad, y dejaron de lado cuestiones más decisivas. El error estriba en menospreciar lo que estaba en juego al interior de ese debate. Con esto quiero decir que el hecho de que toda o casi toda la campaña presidencial de RN y Fabricio Alvarado se centrara en el rechazo de la diversidad sexual, no era en absoluto una desviación del tema principal. En ese rechazo y en la reivindicación de devolver a los padres el control de la sexualidad de sus hijos (nótese que la voz estudiantil fue acallada sistemáticamente por los medios de comunicación y por los propios candidatos), se jugaba, por el contrario, todo un modelo de gobierno. Se trataba, por un lado, de reactivar el autoritarismo religioso otrora reservado a la Iglesia católica (cuyo papel en la pasada elección nunca fue de decidido rechazo, al menos si se la compara con el papel de la Iglesia de Nicaragua en los últimos disturbios ocurridos en ese país); pero, por otro, de reactivar modos de gubernamentalidad pastorales, dirigistas y verticales en el nivel del Estado. La particularidad de esta propuesta residía en que, pese al gesto de devolver a las instituciones "paraestatales" una autoridad supuestamente minada por el Estado, en realidad de lo que se trataba era de volver a centralizar el poder en complicidad con lo que queda de las antiguas élites económicas. La sexualidad, así, no era un tema irrelevante; por el contrario, era la punta de lanza de todo un proyecto autoritario que prometía restituir formas de gobierno que se han venido erosionando en el país (de ahí, de nuevo, la metáfora de la "restauración").

Quisiera concluir señalando una cuestión. Si es verdad que la sexualidad ha sido un eje de gobierno fundamental a lo largo de la historia, también hay que decir que las rebeliones sexuales han tocado desde siempre puntos neurálgicos del poder. De ahí que diversos movimientos sociales hayan 
optado, según sea el momento, por tornar de dominio público lo que según el ordenamiento moderno pertenece al privado (piensen en la reivindicación feminista del espacio doméstico como espacio público), o bien por sustraer al dominio público lo que se supone que pertenece al dominio privado (es el caso de la reivindicación liberal de que cada quien puede hacer lo que quiera con su cuerpo en el ámbito privado).

En síntesis, si la sexualidad es un vector que permite el gobierno de la carne individual al tiempo que el gobierno de las poblaciones, no es menos cierto que las insurrecciones sexuales constituyen, asimismo, formas de rebelión individuales y poblacionales. Cuando nos rebelamos a obedecer en la sexualidad, nos rebelamos potencialmente a que nuestros cuerpos y nuestras vidas sean gobernadas por otros desde afuera. Y si antes hablé de una crisis histórica de gubernamentalidad, acaso sea el momento de inventar nuevas formas de autogobierno que permitan gestionar no solo nuestros propios deseos individuales, sino también nuestras vidas como poblaciones.

\section{Referencias bibliográficas}

Béjin, A. (1987). Crepúsculo de los psicoanalistas, aurora de los sexólogos. En P. Ariès, A. Béjin y M. Foucault (Comps.), Sexualidades occidentales (pp. 249-282). Barcelona: Paidós.

Butler, J. y Spivak, G. (2009). ¿Quién le canta al Estado-Nación? Lenguaje, política, pertenencia. Buenos Aires: Paidós.

Canguilhem. (2011). Lo normal y lo patológico. Buenos Aires: Amorrortu.

Echavarren, R. (Comp.). (2009). Porno y postporno. Montevideo: HUM.

Foucault, M. (2002). Los anormales (Trad. H. Pons). Buenos Aires: Fondo de Cultura Económica. . (2004). La inquietud de sí (Trad. T. Segovia). México: Siglo XXI.

- (2005). La voluntad de saber. (Trad. U. Guiñazú). México: Siglo XXI.

. (2009). Seguridad, territorio y población (Trad. H. Pons). Buenos Aires: Fondo de

Cultura Económica.

. (2010). El gobierno de sí y de los otros. Buenos Aires: Fondo de Cultura Económica.

Tin, L-G. (2012). La invención de la cultura heterosexual (Trad. L. Sclavo). Buenos Aires:

El cuenco de plata.

Vigarello, G. (2011). Historia de la obesidad. Metamorfosis de la gordura. Buenos Aires: Nueva Visión. 
